\title{
Poluição hídrica e seu potencial genotóxico: Uma análise da bacia do rio Doce após o rompimento da barragem de Fundão
}

\author{
Hydric pollution and its genotoxic potential: An analysis of the Doce river basin after the Fundao \\ dam failure
}

La contaminación del agua y su potencial genotóxico: Un análisis de la cuenca del río Doce tras el derrumbe de la presa de Fundão

\author{
Isabela Brescia Soares de Souza \\ ORCID: https://orcid.org/0000-0002-0824-1058 \\ Universidade Federal de São João del-Rei, Brasil \\ E-mail: isabelabss@hotmail.com \\ Lara Luiza Freitas de Oliveira \\ ORCID: https://orcid.org/0000-0002-2115-0943 \\ Universidade Federal de São João del-Rei, Brasil \\ E-mail: luizalara422@gmail.com \\ Ralph Gruppi Thomé \\ ORCID: https://orcid.org/0000-0002-1779-5036 \\ Universidade Federal de São João del-Rei, Brasil \\ E-mail: ralph@ufsj.edu.br \\ Hélio Batista dos Santos \\ ORCID: https://orcid.org/0000-0001-6813-8522 \\ Universidade Federal de São João del-Rei, Brasil \\ E-mail: hbsufsj@gmail.com \\ Magna Cristina de Paiva \\ ORCID: https://orcid.org/0000-0001-9375-7261 \\ Universidade Federal de São João del-Rei, Brasil \\ E-mail: magnacpaiva@ufsj.edu.br \\ Farah Maria Drumond Chequer \\ ORCID: https://orcid.org/0000-0003-3514-2132 \\ Universidade Federal de São João del-Rei, Brasil \\ E-mail: farahchequer@ufsj.edu.br
}

\begin{abstract}
Resumo
Objetivos: Analisar evidências científicas existentes que descrevam os efeitos genotóxicos, mutagênicos ou citotóxicos associados a amostras coletadas na bacia do rio Doce, após o rompimento da barragem. E analisar a taxa de mortalidade por câncer (MC) entre a população de Mariana, Governador Valadares (GV) e Ipatinga, em Minas Gerais, e Colatina e Linhares, no Espírito Santo, cidades relacionadas com o rio Doce. Métodos: Foram utilizadas cinco bases de dados: PubMed, SciELO, Science Direct, Scopus e Google Acadêmico, os descritores: "Dam", "Fundao", "Mariana", "genotoxic" e operador booleno "AND", selecionando estudos que descreviam os efeitos tóxicos de amostras coletadas no rio Doce. Além disso foram coletados dados de MC no "Atlas de Mortalidade OnLine" do INCA, para os períodos de 2013-2015 e 2016-2018, notificados nas cidades estudadas. Resultados: Selecionou-se 4 estudos acerca dos efeitos genotóxicos. As taxas de MC obtidas por 100.000 habitantes nas cidades mencionadas e períodos definidos acima, foram observados aumentos em GV, Ipatinga, Colatina e Linhares, mas redução em Mariana. Conclusão: Sugere-se que as amostras analisadas possuem potencial genotóxico possivelmente associados à poluição por rejeitos de mineração. Observou-se que nas cidades abastecidas hidricamente pelo rio Doce, ou com relação com pesqueira, a MC aumentou após o desabamento, sugerindo uma relação entre a mortalidade por câncer e o abastecimento hídrico proveniente do rio Doce. No entanto, são necessários mais estudos para que se possa confirmar essa relação.
\end{abstract}

Palavras-chave: Toxicologia; Genotoxicidade; Mortalidade; Neoplasias; Metais pesados.

\section{Abstract}

Objectives: To analyze existing scientific evidence that describes the genotoxic, mutagenic or cytotoxic effects associated with those collected in the Doce river basin, after the dam burst. And to analyze a cancer mortality rate (CM) among a population of Mariana, Governador Valadares (GV) and Ipatinga, in Minas Gerais, and Colatina and Linhares, in Espirito Santo, cities related to the Doce river. Methods: Five databases were used: PubMed, SciELO, 
Science Direct, Scopus and Google Scholar, the descriptors: "Dam", "Fundao", "Mariana", "genotoxic" and boolean operator "AND", study studies that described the toxic effects of collected in the Doce river. In addition, CM data were collected from INCA's "On-Line Mortality Atlas", for the periods 2013-2015 and 2016-2018, reported in the cities studied. Results: Four studies were selected on the genotoxic effects. The rates of CM employees per 100,000 inhabitants in the cities mentioned and defined above, there were increases in GV, Ipatinga, Colatina and Linhares, but reduction in Mariana. Conclusion: It is suggested that the analyzed ones have genotoxic potential associated with the generation by mining tailings. It was observed that in cities supplied hydric by the Doce river, or in relation to fishing, a CM increased after the collapse, suggesting a relationship between cancer mortality and water supply from the Doce river. However, studies are more studies to confirm this relationship.

Keywords: Toxicology; Genotoxicity; Mortality; Neoplasms; Heavy metals.

\section{Resumen}

Objetivos: Analizar la evidencia científica existente que describe los efectos genotóxicos, mutagénicos o citotóxicos asociados a los recolectados en la cuenca del río Doce, luego del estallido de la presa. Y analizar la tasa de mortalidad por cáncer (CM) en una población de Mariana, Governador Valadares (GV) e Ipatinga, en Minas Gerais, y Colatina y Linhares, en Espírito Santo, municipios afines al río Doce. Métodos: se utilizaron cinco bases de datos: PubMed, SciELO, Science Direct, Scopus y Google Scholar, los descriptores: "Dam", "Fundao", "Mariana", "genotóxico" y operador booleano "AND", estudios de estudios que describieron el efectos de toxicidad de capturados en el río Doce. Además, los datos de CM fueron recolectados del "Atlas de Mortalidad en Línea" de INCA, para los períodos 20132015 y 2016-2018, reportados en las ciudades estudiadas. Resultados: Se seleccionaron cuatro estudios sobre los efectos genotóxicos. En las tasas de empleados de MC por 100.000 habitantes en las ciudades mencionadas y definidas anteriormente, hubo aumentos en GV, Ipatinga, Colatina y Linhares, pero una reducción en Mariana. Conclusión: Se sugiere que los analizados tienen potencial genotóxico asociado a la generación de residuos mineros. Se observó que en las ciudades abastecidas de agua por el río Doce, o en relación a la pesca, la CM aumentó después de la ruptura, lo que sugiere una relación entre la mortalidad por cáncer y el suministro de agua en el río Doce. Sin embargo, los estudios son más estudios para confirmar esta relación.

Palabras clave: Toxicología; Genotoxicidad; Mortalidad; Neoplasias; Metales pesados.

\section{Introdução}

A água é essencial à vida na terra e a sua qualidade está diretamente relacionada à saúde humana e animal, bem como o equilíbrio ambiental (Souza et al., 2016). Neste contexto, destacam-se os cursos de água, cuja poluição por resíduos de origens diversas pode interferir na vida que cerca.

A bacia do rio Doce inclui os rios do Carmo, Piracicaba, Santo Antônio, Corrente Grande, Suaçuí Pequeno, Suaçuí Grande, São José e Pancas, Casca, Matipó, Caratinga/Cuieté, Manhuaçu, Guandu e Santa Joana, sendo o maior deles o rio que dá seu nome. O rio Doce é um dos cursos de água mais importantes da região sudeste do Brasil, com mais de $835 \mathrm{~km}$ de extensão percorrendo os Estados de Minas Gerais e Espírito Santo e de grande relevância socioeconômica para a região (ANA, 2016).

Em 5 de novembro de 2015, ocorreu o rompimento da barragem de rejeitos de minérios de Fundão (Empresa Samarco - Mariana / MG), descarregando aproximadamente 60 milhões de metros cúbicos de rejeitos de mineração de ferro sobre o rio Gualaxo, desaguando no rio Doce e afetando toda a extensão à jusante, até o Espírito Santo na região estuarina no município de Linhares (IBAMA, 2015; Fernandes et al., 2016).

A lama de rejeitos que se depositou na bacia do rio Doce alterou a sua composição química (Segura et al., 2016; Omachi et al., 2018), sendo que grande parte deste material ficou depositado nas margens e no próprio canal dos rios (Hatje et al., 2017). Um dos maiores impactos foi a alteração das características físico-químicas da água (Foesch et al., 2020) que resultou na morte de milhares de peixes e invertebrados, além de impossibilitar a pesca, o uso da água na agricultura e, até mesmo, o crescimento de plantas na região, caracterizando assim o maior desastre ambiental da história do Brasil (Escobar, 2015). Destaca-se que estudos realizados com mais três anos após o desastre, foi registrado efeitos tóxicos de metais presentes na água em órgãos de peixes, como fígado e brânquias (Weber et al., 2020; Macêdo et al., 2020). 
A bacia do rio Doce é densamente povoada com grandes municípios que utilizam a água do rio Doce para abastecimento ou recreação, além da população ribeirinha de pescadores profissionais e amadores que se valiam da vasta ictiofauna da bacia para sobrevivência (Jankowsky et al., 2020).

Perante o exposto, a presente revisão tem como objetivos realizar uma análise das evidências científicas existentes até o presente momento que descrevam os efeitos genotóxicos, mutagênicos ou citotóxicos causados pelos rejeitos de mineração inseridos após o rompimento da barragem de Fundão ao meio ambiente, da bacia do rio Doce. Além disso, analisar a taxa de mortalidade por câncer nas cidades de Mariana, Governador Valadares, Ipatinga, Colatina e Linhares, as quais guardam proximidade ao rio Doce (Figura 1).

Figura 1: Visão de satélite da Bacia do rio Doce através dos estados de Minas Gerais e Espírito Santo figurando as cidades de Mariana, ponto zero do rompimento, Ipatinga, Governador Valadares, Colatina e Linhares, banhadas pelo rio.

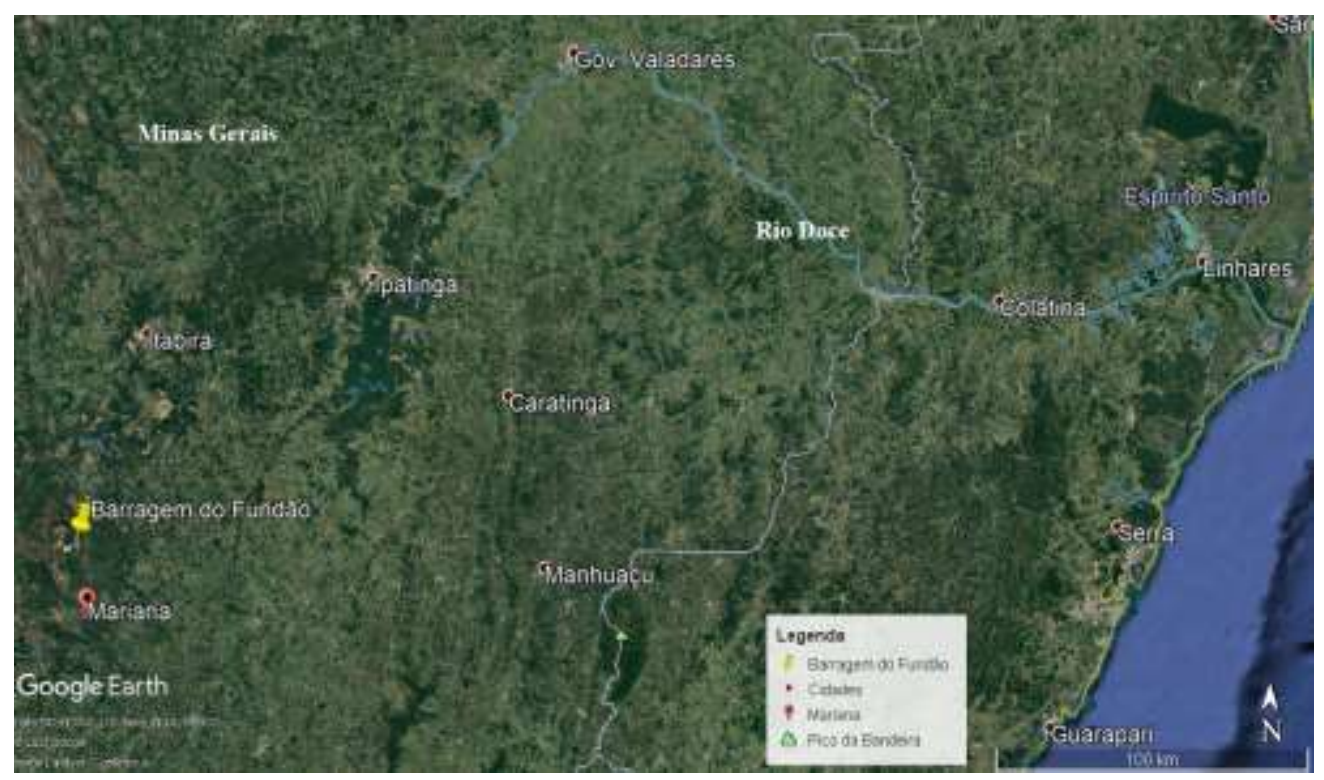

Fonte: Google Earth (2021).

\section{Metodologia}

Este estudo foi elaborado em duas etapas, a seguir: 1) revisão narrativa, de caráter qualitativo. Segundo Ludke \& André (1986, cap.3), "os focos de observação nas abordagens qualitativas de pesquisa são determinados basicamente pelos propósitos específicos do estudo, que por sua vez derivam de um quadro teórico geral, traçado pelo pesquisador", que neste presente estudo focou no levantamento sobre os efeitos genotóxicos, mutagênicos ou citotóxicos causados pelos rejeitos de mineração inseridos após o rompimento da barragem de Fundão ao meio ambiente, da bacia do rio Doce. 2) análise de dados de domínio público sobre a taxa de mortalidade por câncer na população residente de cidades que foram afetadas diretamente ou indiretamente pelo derramamento da barragem do Fundão.

\subsection{Etapa 1: Elaboração da revisão narrativa}

Foi conduzida uma revisão narrativa, método útil em descrever "o estado da arte" de um determinado assunto, sob ponto de vista teórico ou contextual, permitindo a construção de uma análise da literatura científica na interpretação e análise crítica do autor, como descrito por Rother (2007).

A presente revisão foi escrita utilizando-se das evidências científicas relatadas na literatura visando analisar os efeitos genotóxicos, mutagênicos ou citotóxicos causados pela descarga de rejeito de mineração nas cidades de Mariana, Ipatinga, 
Governador Valadares, Colatina e Linhares. Para compor esta revisão foram realizadas buscas de informações em cinco bases de dados: PubMed, SciELO, ScienceDirect, Scopus e Google Acadêmico, no período de 1 a 8 de julho de 2020. Para essas buscas foram utilizados os descritores: "Dam", "Fundao", "Mariana", "genotoxic", juntamente com o operador booleno "AND".

Todos os artigos encontrados foram contabilizados e as publicações em duplicatas foram retiradas. Adicionalmente, após a leitura de títulos e resumos, artigos que não respondiam ao tema de interesse ou que não possuíam as variáveis selecionadas para o estudo foram excluídos. Nos casos em que as informações contidas nos títulos e resumos não foram suficientes para uma análise indubitável, foi realizado a leitura na íntegra do artigo. Foi realizada, também, a busca de referências encontradas nos estudos selecionados, visando maximizar o banco de informações.

Foram considerados elegíveis artigos publicados entre 2015 e 2020, nos idiomas inglês, português ou espanhol, sendo este período escolhido considerando a data do derramamento da barragem do Fundão (Novembro de 2015). Foram considerados os artigos que descrevessem os efeitos genotóxicos, mutagênicos ou citotóxicos em amostras coletadas na bacia do rio Doce após o rompimento da barragem de Fundão. Foram excluídos: revisões, relatórios, catálogos, editoriais, notícias, relatos de casos, comentários, resultados de dissertação ou teses, resumos publicados em anais de congresso ou em revistas científicas.

As variáveis consideradas relevantes e coletadas de cada estudo selecionado incluíram autor, ano de publicação, localidade do estudo, amostra impactada analisada, quantidade amostral, teste realizado, condições de exposição, grupo controle, descrição dos efeitos tóxicos (genotóxicos/mutagênicos/citotóxicos) e as limitações descritas do estudo.

\subsection{Etapa 2: Análise de taxa de mortalidade por câncer}

Foram analisados os dados acerca da mortalidade por câncer entre a população das cidades mineiras (Mariana, Governador Valadares e Ipatinga) e capixabas (Colatina e Linhares), banhadas pelo rio Doce, ou, no caso de Mariana, o marco zero para o derramamento de rejeitos (ANA, 2016), contidos no "Atlas de Mortalidade On-line" organizado pelo Instituto Nacional de Câncer (INCA). Foram analisados dados referentes a dois períodos, sendo 2013 a 2015 e 2016 a 2018, respectivamente antes e após do derramamento da barragem do Fundão. Foram consideradas para essa análise as variáveis sexo e tipo de câncer, registrados em agrupamentos disponibilizados pelo INCA, em taxa bruta, ou seja, número de óbitos a cada 100.000 habitantes (Tabela 1). Após a coleta dos dados foi analisada a taxa de crescimento de óbitos por câncer nas localidades e períodos citados e foram identificados os tipos tumorais com maior índice de óbitos. 
Tabela 1: Lista de Classificação Internacional de Doenças (CID) das neoplasias analisadas e suas correspondências segundo o Instituto Nacional de Câncer (INCA).

\begin{tabular}{cc}
\hline CID & TIPO DE CANCER \\
\hline C00-10/C07-08 & Lábio, língua, cavidade oral e orofaringe \\
C12-13 & Hipofaringe \\
C18-21 & Intestino Grosso canal ânus e ânus \\
C23-24 & Vesícula biliar e vias biliares extra hepáticas \\
C30-31 & Cavidade nasal, ouvido médio e seios da face \\
C33-34 & Traqueia, brônquios e pulmões \\
C37-38 & Outros órgãos torácicos \\
C40-41 & Ossos, articulações e cartilagens articulares \\
C47+C49 & Nervos periféricos, sistema nervoso autônomo e partes moles (tecidos conjuntivo, \\
C64-66, C68 & subcutâneo e outros tecidos moles) \\
C70-72 & Rim, Vias urinárias exceto bexiga \\
C81-85, C96 & Sistema Nervoso Central \\
C91-95 & Linfoma \\
C54-55 & Leucemia \\
\hline
\end{tabular}

Legenda: CID - Classificação Estatística Internacional de Doenças e Problemas Relacionados com a Saúde. Fonte: Dados coletados no Atlas de Mortalidade On-line, organizado pelo Instituto Nacional de Câncer (INCA) (2021).

\section{Resultados}

\subsection{Revisão Narrativa}

Um total de 48 artigos com informações referentes ao rio Doce após o rompimento da barragem do Fundão foram contabilizados. Após exclusão dos artigos (em duplicata, a partir da leitura do título ou resumo, e após a leitura na íntegra), 4 artigos foram incluídos nesta revisão (Figura 2). 
Figura 2: Fluxograma que resume a metodologia empregada na revisão narrativa acerca dos efeitos genotóxicos/ mutagênicos/citotóxicos de amostras do rio Doce. Foram utilizados os seguintes descritores: "Dam", "Fundao", "Mariana", "genotoxic".

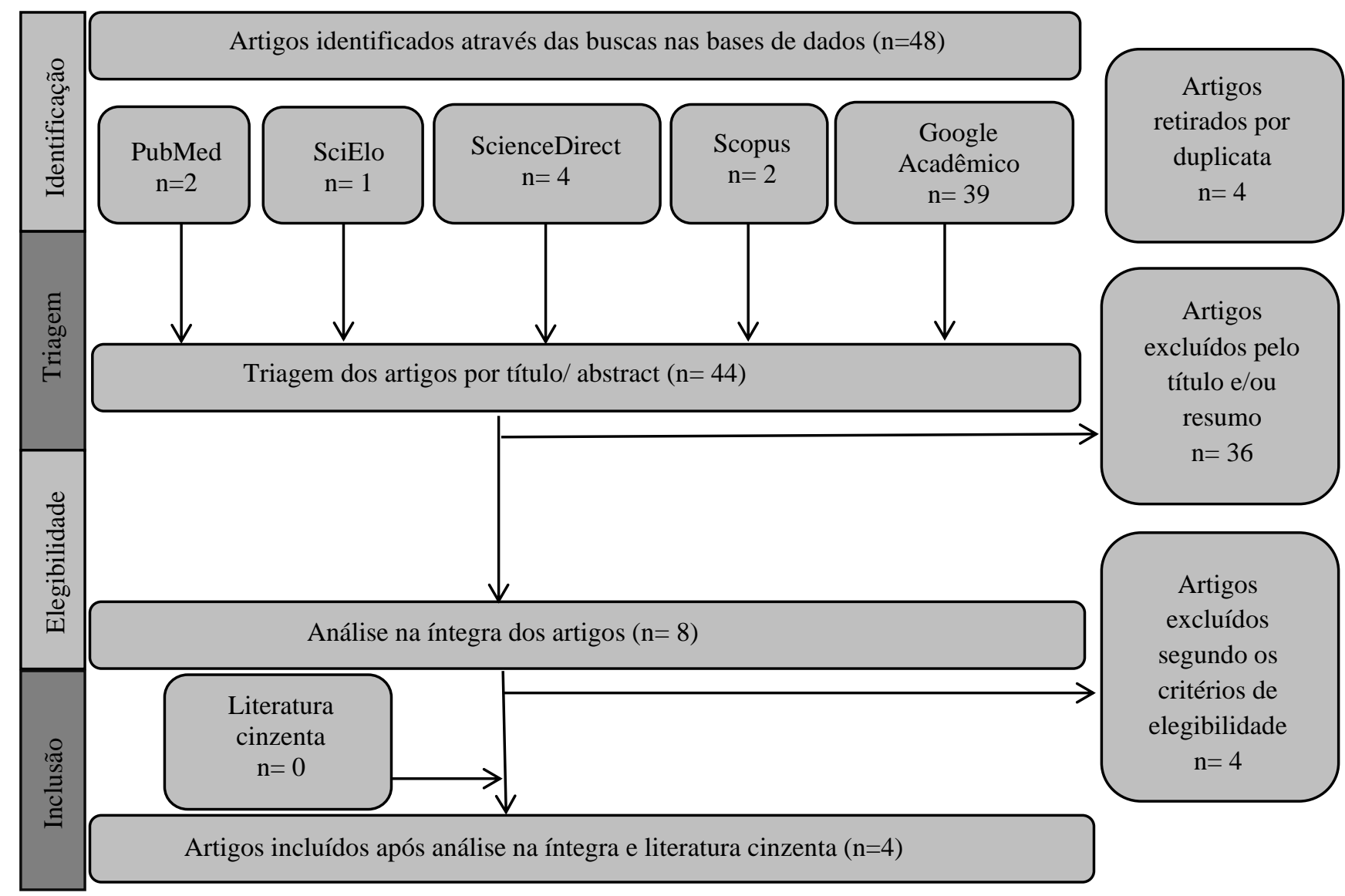

Fonte: Autores (2020).

A Tabela 2 apresenta os estudos que analisaram amostras de água, solo e sedimentos do rio Doce após o rompimento da barragem de Fundão, os quais utilizaram bioindicadores para investigar os possíveis efeitos tóxicos proporcionados pelo contato com essas amostras. Vale ressaltar que níveis aumentados de metais pesados, mais especificamente o ferro ( $\mathrm{Fe}$ ), manganês (Mn) e o arsênio (As) foram observados.

Gomes e colaboradores (2019) realizaram a análise do potencial genotóxico da água para peixes Geophagus brasiliensis, incluindo exposição a água do sistema de abastecimento urbano e água do rio Doce antes e após o rompimento da barragem de Fundão. De acordo com esses autores, efeitos genotóxicos caracterizados pelo aumento de 3,50\% no número de micronúcleos e de $120 \%$ índices de danos ao DNA (Teste de Cometa) foram observados nos animais expostos a água do rio Doce impactada pelo rejeito de mineração após o rompimento da barragem. No entanto também foram apresentadas reações genotóxicas nos testes com a água coletada anteriormente ao derramamento sendo que esses valores foram de 2,50\% para micronúcleo e $200 \%$ para teste de cometa em relação ao controle.

Em outro estudo, peixes Oreochromis niloticus foram expostos a diferentes concentrações de manganês $(0,0 ; 0,2 ; 1,5$ e 2,9 mg/L) (Coppo et al., 2018), as quais foram encontradas nas amostras de água coletadas no rio Doce e são consideradas altas de acordo com o CONAMA $(>0,1 \mathrm{mg} / \mathrm{L})$. Neste estudo, foi observado um aumento no número de micronúcleos eritrocitários e dos índices de danos ao DNA nos animais, corroborando com a genotoxicidade resultante da exposição a altas concentrações de manganês (Coppo et al., 2018). 
Potencial citotóxico também foi atribuído à água do rio Doce (Ipatinga/MG) sobre sementes de Allium cepa, popularmente conhecida como cebola e amplamente utilizada na alimentação, no estudo realizado por Quadra e colaboradores (2018) (Tabela 2). Dentre os efeitos destacaram-se alterações nos índices mitóticos e de fase (aumento do índice de prófase e índices reduzidos de metáfase, anáfase e telófase), maior frequência de aberrações cromossômicas (pontes, quebras cromossômicas, c-metáfases, segregação posterior, perda cromossômica e micronúcleos), além da diminuição no índice de germinação. Maiores concentrações de água, ou seja, maiores volumes de água do rio Doce, resultaram em maiores efeitos genotóxicos (Quadra et al., 2018).

Da mesma forma, Segura e colaboradores (2016) mostraram o potencial genotóxico, mutagênico e citotóxico da água, solo e sedimentos coletados do rio Doce sobre bioindicadores (sementes de Allium cepa e células HepG2).

Tabela 2: Características dos artigos selecionados que analisaram amostras da bacia do rio Doce, após o rompimento da barragem de Fundão.

\begin{tabular}{|c|c|c|c|c|c|c|c|}
\hline ESTUDOS & \multicolumn{5}{|c|}{ MÉTODO } & \multicolumn{2}{|c|}{ RESULTADOS } \\
\hline $\begin{array}{l}\text { Autor/ ano/ } \\
\text { localidade }\end{array}$ & $\begin{array}{c}\text { Amostra } \\
\text { impactada } \\
\text { analisada e } \\
\text { localidade }\end{array}$ & $\mathrm{n}$ amostral & $\begin{array}{c}\text { Teste } \\
\text { realizado }\end{array}$ & $\begin{array}{l}\text { Condições de } \\
\text { exposição }\end{array}$ & Grupo controle & $\begin{array}{l}\text { Descrição dos } \\
\text { efeitos tóxicos }\end{array}$ & $\begin{array}{c}\text { Limitações do } \\
\text { estudo }\end{array}$ \\
\hline $\begin{array}{c}\text { Gomes et al., 2019, } \\
\text { Brasil }\end{array}$ & $\begin{array}{c}\text { Água / } \\
\text { Colatina - ES }\end{array}$ & $\begin{array}{l}80 \mathrm{~L} \text { de água } \\
/ 24 \text { peixes }\end{array}$ & $\begin{array}{c}\text { Ensaio do } \\
\text { cometa; Teste } \\
\text { de micronúcleo }\end{array}$ & $\begin{array}{l}\text { Peixes expostos } \\
\text { por } 96 \text { horas } \\
\text { em } 5 \text { litros de } \\
\text { água do rio } \\
\text { Doce }\end{array}$ & $\begin{array}{c}\text { Água do sistema } \\
\text { urbano de } \\
\text { abastecimento; } \\
\text { Água do rio } \\
\text { Doce antes do } \\
\text { afluxo de rejeitos }\end{array}$ & $\begin{array}{l}\text { Aumento no } \\
\text { número de } \\
\text { micronúcleos } \\
\text { eritrocitários; } \\
\text { Aumento no índice } \\
\text { de danos ao DNA }\end{array}$ & $\begin{array}{l}\text { Água do rio } \\
\text { Doce já } \\
\text { apresentava } \\
\text { potencial } \\
\text { genotóxico } \\
\text { antes do } \\
\text { acidente }\end{array}$ \\
\hline $\begin{array}{c}\text { Coppo et al., 2018, } \\
\text { Brasil }\end{array}$ & Água / - & $\begin{array}{l}6 \mathrm{~L} \text { (Aquário } \\
\text { individual)/ } \\
32 \\
\text { Oreochromis } \\
\text { niloticus } \\
\text { jovens }\end{array}$ & $\begin{array}{c}\text { Ensaio do } \\
\text { cometa; Teste } \\
\text { de micronúcleo }\end{array}$ & $\begin{array}{c}\text { Peixes expostos } \\
\text { por } 96 \text { horas a } \\
\text { diferentes } \\
\text { concentrações } \\
\text { de manganês } \\
\text { (Mn) }\end{array}$ & $\begin{array}{c}\text { Peixe com } \\
\text { ciclofosfamida } \\
\text { (CPM); } \\
\text { Concentração de } \\
\text { Mn igual a } 0 \\
\text { mg/L }\end{array}$ & $\begin{array}{c}\text { Aumento na } \\
\text { formação de } \\
\text { micronúcleos } \\
\text { eritrocitários; } \\
\text { Aumento no índice } \\
\text { de danos ao DNA }\end{array}$ & $\begin{array}{l}\text { Pode haver } \\
\text { efeitos } \\
\text { sinérgicos de } \\
\text { outros metais }\end{array}$ \\
\hline $\begin{array}{c}\text { Quadra et al., 2018, } \\
\text { Brasil, Estados } \\
\text { Unidos }\end{array}$ & $\begin{array}{l}\text { Água / } \\
\text { Próximo a } \\
\text { Ipatinga - } \\
\text { MG }\end{array}$ & $\begin{array}{l}3 \text { amostras de } \\
\text { água (duas } \\
\text { regiões } \\
\text { impactadas e } \\
\text { uma não } \\
\text { impactada) }\end{array}$ & Teste Allium & $\begin{array}{c}\text { Sementes } \\
\text { expostas por } 24 \\
\text { horas em } \\
\text { soluções de } 20, \\
40,60,80 \text { e } \\
100 \% \text { de água } \\
\text { do rio Doce }\end{array}$ & $\begin{array}{c}\text { Água coletada } \\
\text { em um local não } \\
\text { impactado do rio } \\
\text { Doce, próximo a } \\
\text { Linhares - ES }\end{array}$ & $\begin{array}{l}\text { Alterações nos } \\
\text { índices mitóticos e } \\
\text { de fase; Maior } \\
\text { frequência de } \\
\text { aberrações } \\
\text { cromossômicas; } \\
\text { Diminuição no } \\
\text { índice de } \\
\text { germinação }\end{array}$ & N/A* \\
\hline $\begin{array}{l}\text { Segura et al., 2016, } \\
\text { Brasil }\end{array}$ & $\begin{array}{c}\text { Água, solo, } \\
\text { sedimento/ } \\
\text { Bento } \\
\text { Rodrigues - } \\
\text { MG }\end{array}$ & $\begin{array}{l}44 \text { amostras } \\
\text { de água, solo } \\
\text { ou sedimento }\end{array}$ & $\begin{array}{c}\text { Ensaio do } \\
\text { cometa; Teste } \\
\text { de } \\
\text { micronúcleo;T } \\
\text { este Allium }\end{array}$ & $\begin{array}{c}\text { Células e } \\
\text { sementes } \\
\text { expostas por } 24 \\
\text { horas em } 15 \mathrm{~g} \\
\text { de solo / } \\
\text { sedimentos ou } \\
5 \text { mL de água }\end{array}$ & $\begin{array}{l}\text { Água deionizada } \\
(-) \text { e metil- } \\
\text { metanossulfonato } \\
(+)\end{array}$ & $\begin{array}{c}\text { Aumento na } \\
\text { formação de } \\
\text { micronúcleos; } \\
\text { Aumento } \\
\text { significativo no } \\
\text { índice de danos ao } \\
\text { DNA }\end{array}$ & $\begin{array}{l}\text { Dificuldade em } \\
\text { identificar } \\
\text { todos os } \\
\text { poluentes } \\
\text { presentes nas } \\
\text { amostras } \\
\text { responsáveis } \\
\text { pelos efeitos } \\
\text { tóxicos }\end{array}$ \\
\hline
\end{tabular}

Legenda: $* \mathrm{~N} / \mathrm{A}=$ não se aplica.

Fonte: Dados coletados dos artigos selecionados para compor a presente revisão (2020). 


\subsection{Análise da taxa de mortalidade por câncer}

É conhecido que a poluição acarreta alterações nos organismos vivos, que podem ser leves a grave, imprimindo risco de morte. Dentre elas, pode ser citado o câncer, que cada vez mais tem apontado como causa o desequilíbrio, incluindo o ambiental (Braz \& Longo, 2021). Nesse contexto, buscou-se analisar os dados de mortalidade por câncer entre a população das cidades mais relacionadas com a bacia do rio Doce considerando a possível interferência da água utilizada pela população.

Segundo o Atlas de Mortalidade On-line (INCA) em Mariana, os dados de mortalidade por câncer para o período de 2013-2015 e 2016-2018 foram, respectivamente, de 47,52 e 47,55/100.000 para ambos os sexos. A região do município foi afetada diretamente pelo derramamento da barragem de Fundão em 2015, mas a população da cidade não tem o abastecimento hídrico proveniente do rio Doce (SEDRU, 2016). A Tabela 3 apresenta os dados da mortalidade agrupados por tipos de câncer notificados na cidade de Mariana nos períodos analisados. No entanto, é possível destacar que os tipos neoplásicos com maior taxa de mortalidade foram do sistema nervoso central; traqueia, brônquios e pulmões; vesícula biliar e vias biliares extrahepáticas. Deve ser destacado que nenhum dado de mortalidade por câncer na hipofaringe, cavidade nasal, ouvido médio e seios da face foram notificados.

Analisando os índices gerais é possível notar que houve uma pequena redução na taxa de mortalidade global por câncer na população da cidade de Mariana após o rompimento da barragem. Os dados analisados quanto ao gênero, mostraram que a taxa de mortalidade é menor entre a população feminina nos dois períodos investigados $(78,56$ e 66,55\%/100.000 habitantes), além de ter ocorrido uma queda de 15,29\% no período de 2016-2018. Vale ressaltar que uma leve diminuição da taxa de mortalidade $(1,02 \%)$ foi também observada entre o sexo masculino, para o qual os índices de mortalidade foram de 95,57/100.000 habitantes (2013-2015) e 94,59/100.000 habitantes (2016-2018). 
Tabela 3: Dados de mortalidade por câncer na cidade de Mariana-MG nos períodos de 2013-2015 e 2016-2018 por 100.000 habitantes quanto ao registro considerando a classificação internacional de doença (CID).

\begin{tabular}{|c|c|c|c|c|c|c|}
\hline \multirow{2}{*}{ Mariana } & \multicolumn{3}{|c|}{ 2013-2015/100.00 habitantes } & \multicolumn{3}{|c|}{ 2016-2018/100.000 habitantes } \\
\hline & Todos & $\mathbf{F}$ & $\mathbf{M}$ & Todos & $\mathbf{F}$ & $\mathbf{M}$ \\
\hline Todos os tipos de câncer & 47,52 & 78,56 & 95,57 & 47,55 & 66,55 & 94,59 \\
\hline $\begin{array}{c}\text { Lábio, língua, cavidade oral e } \\
\text { orofaringe } \\
\text { (C00-10/C07-08) }\end{array}$ & 2,29 & 0,00 & 4,61 & 1,13 & 0,00 & 2,28 \\
\hline $\begin{array}{c}\text { Intestino Grosso canal ânus e } \\
\text { ânus (C18-21) }\end{array}$ & 1,72 & 2,28 & 3,45 & 1,13 & 2,26 & 7,98 \\
\hline $\begin{array}{l}\text { Vesícula biliar e vias biliares } \\
\text { extra hepáticas (C23-24) }\end{array}$ & 2,29 & 4,55 & 3,45 & 0,57 & 1,13 & 0,00 \\
\hline $\begin{array}{l}\text { Traqueia, brônquios e pulmões } \\
\qquad \text { (C33-34) }\end{array}$ & 2,29 & 5,69 & 4,61 & 6,80 & 3,38 & 13,68 \\
\hline $\begin{array}{l}\text { Outros órgãos torácicos } \\
\text { (C37-38) }\end{array}$ & 0,00 & 0,00 & 0,00 & 0,00 & 0,00 & 0,00 \\
\hline $\begin{array}{c}\text { Ossos, articulações e cartilagens } \\
\text { articulares } \\
\text { (C40-41) }\end{array}$ & 0,57 & 1,14 & 0,00 & 0,57 & 0,00 & 1,14 \\
\hline $\begin{array}{l}\text { Nervos periféricos, sistema } \\
\text { nervoso autônomo e partes moles } \\
\text { (tecidos conjuntivo, subcutâneo e } \\
\text { outros tecidos moles) (C47+C49) }\end{array}$ & 0,57 & 0,00 & 0,00 & 0,00 & 0,00 & 0,00 \\
\hline $\begin{array}{l}\text { Rim, Vias urinárias exceto } \\
\text { bexiga }(\mathrm{C} 64-66, \text { C68) }\end{array}$ & 0,57 & 1,14 & 1,15 & 0,57 & 2,26 & 1,14 \\
\hline $\begin{array}{c}\text { Sistema Nervoso Central } \\
(\mathrm{C} 70-72)\end{array}$ & 3,43 & 6,83 & 4,61 & 1,13 & 2,26 & 5,70 \\
\hline Linfoma (C81-85, C96) & 1,14 & 0,00 & 2,30 & 1,70 & 3,38 & 1,14 \\
\hline Leucemia (C91-95) & 0,57 & 1,14 & 5,76 & 1,13 & 2,26 & 5,70 \\
\hline $\begin{array}{l}\text { Corpo uterino e útero, SOE } \\
\text { (C54-55) }\end{array}$ & 0,57 & 1,14 & - & 2,27 & 4,51 & - \\
\hline
\end{tabular}

Legenda: $\mathrm{SOE}=$ Sem outras especificações .

Fonte: Dados coletados no Atlas de Mortalidade On-line, organizado pelo Instituto Nacional de Câncer (INCA) (2021).

Na cidade de Governador Valadares as taxas de mortalidade para o período de 2013-2015 foram de 52,11/100.000 habitantes, enquanto que no período de 2016-2018 foram de 61,07/100.000 habitantes, representando um aumento de 17,19\%. Considerando a divisão da população por gênero é possível observar que os índices de mortalidade gerais são maiores para a população masculina $(119,07$ e 127,23) em relação à feminina $(100,24$ e 112,84), mas o crescimento de mortalidade para a população feminina, $12,57 \%$, foi maior que o da masculina, 6,85\% após o rompimento da barragem. Destaca-se que o abastecimento hídrico desta cidade é proveniente do rio Doce (SEDRU, 2016; ANA, 2016). Os tipos neoplásicos mais comuns foram descritos na traqueia, brônquios e pulmões; intestino grosso e ânus, conforme mostra a Tabela 4. Além disso vale ressaltar que não houve registro de mortalidade para neoplasias na cavidade nasal, ouvido médio e seios da face. 
Tabela 4: Dados de mortalidade por câncer na cidade de Governador Valadares-MG nos períodos de 2013-2015 e 2016-2018 por 100.000 habitantes quanto ao registro considerando a classificação internacional de doença (CID).

\begin{tabular}{|c|c|c|c|c|c|c|}
\hline \multirow{2}{*}{ Governador Valadares } & \multicolumn{3}{|c|}{ 2013-2015/100.00 habitantes } & \multicolumn{3}{|c|}{ 2016-2018/100.000 habitantes } \\
\hline & Todos & $\mathbf{F}$ & $\mathbf{M}$ & Todos & $\mathbf{F}$ & $\mathbf{M}$ \\
\hline Todos os tipos de câncer & 52,11 & 100,24 & 119,07 & 61,07 & 112,84 & 127,23 \\
\hline Lábio, língua, cavidade oral e & & & & & & \\
\hline orofaringe & 2,29 & 0,23 & 4,76 & 0,96 & 1,84 & 5,49 \\
\hline (C00-10/C07-08) & & & & & & \\
\hline Hipofaringe (C12-13) & 0,24 & 0,00 & 0,50 & 1,08 & 0,00 & 2,25 \\
\hline $\begin{array}{c}\text { Intestino Grosso canal ânus e } \\
\text { ânus (C18-21) }\end{array}$ & 3,49 & 9,49 & 7,27 & 3,23 & 8,52 & 6,74 \\
\hline $\begin{array}{l}\text { Vesícula biliar e vias biliares } \\
\text { extra hepáticas (C23-24) }\end{array}$ & 0,84 & 1,62 & 1,00 & 0,84 & 3,22 & 1,75 \\
\hline $\begin{array}{l}\text { Traqueia, brônquios e pulmões } \\
\qquad(\mathrm{C} 33-34)\end{array}$ & 7,70 & 11,57 & 16,04 & 6,83 & 10,59 & 14,22 \\
\hline $\begin{array}{l}\text { Outros órgãos torácicos } \\
\qquad \text { (C37-38) }\end{array}$ & 0,12 & 0,23 & 0,00 & 0,12 & 0,23 & 0,25 \\
\hline $\begin{array}{l}\text { Ossos, articulações e } \\
\text { cartilagens articulares }\end{array}$ & 0,72 & 0,93 & 1,50 & 0,84 & 0,69 & 1,75 \\
\hline$(\mathrm{C} 40-41)$ & & & & & & \\
\hline $\begin{array}{l}\text { Nervos periféricos, sistema } \\
\text { nervoso autônomo e partes }\end{array}$ & & & & & & \\
\hline $\begin{array}{l}\text { moles (tecidos conjuntivo, } \\
\text { subcutâneo e outros tecidos } \\
\text { moles) }(\mathrm{C} 47+\mathrm{C} 49)\end{array}$ & 0,36 & 0,69 & 1,25 & 0,84 & 1,61 & 0,50 \\
\hline $\begin{array}{l}\text { Rim, Vias urinárias exceto } \\
\text { bexiga }(\mathrm{C} 64-66, \mathrm{C} 68)\end{array}$ & 0,96 & 1,85 & 1,00 & 0,36 & 0,69 & 2,00 \\
\hline $\begin{array}{l}\text { Sistema Nervoso Central (C70- } \\
\text { 72) }\end{array}$ & 2,29 & 4,40 & 4,01 & 3,35 & 6,45 & 4,24 \\
\hline Linfoma (C81-85, C96) & 1,08 & 1,39 & 1,50 & 0,96 & 1,84 & 4,24 \\
\hline Leucemia (C91-95) & 0,60 & 1,16 & 4,76 & 1,56 & 2,99 & 2,99 \\
\hline $\begin{array}{l}\text { Corpo uterino e útero, SOE } \\
\text { (C54-55) }\end{array}$ & 2,65 & 5,09 & - & 2,28 & 4,38 & - \\
\hline
\end{tabular}

Legenda: $\mathrm{SOE}=$ Sem outras especificações .

Fonte: Dados coletados no Atlas de Mortalidade On-line, organizado pelo Instituto Nacional de Câncer (INCA) (2021).

Um aumento de aproximadamente $2 \%$ na taxa de mortalidade por câncer foi observado nos períodos estudados na cidade de Ipatinga-MG, que assim como GV possui abastecimento hídrico provindo do rio Doce (SEDRU, 2016). Nesta 
cidade, a taxa de mortalidade para o período de 2013-2015 foi de 45,97/100.000 habitantes, enquanto no período de 2016-2018 foram de 46,89/100.000 habitantes. Considerando apenas mulheres as taxas foram de 90,09 para o primeiro período e 91,84 para o segundo e para homens os valores foram de 109,33 e 117,50 respectivamente. É possível inferir que novamente a população masculina apresenta maior mortalidade que a população feminina, porém nesse caso o aumento percentual entre os períodos foi maior na população masculina, $7,47 \%$, do que na feminina, 1,94\%. Os tipos de câncer de maior mortalidade notificados entre a população nessa cidade foram da traqueia, brônquios e pulmões; intestino grosso e ânus (Tabela 5). 
Tabela 5: Dados de mortalidade por câncer na cidade de Ipatinga-MG nos períodos de 2013-2015 e 2016-2018 por 100.000 habitantes quanto ao registro considerando a classificação internacional de doença (CID).

\begin{tabular}{|c|c|c|c|c|c|c|}
\hline \multirow[t]{2}{*}{ Ipatinga } & \multicolumn{3}{|c|}{ 2013-2015/100.00 habitantes } & \multicolumn{3}{|c|}{ 2016-2018/100.000 habitantes } \\
\hline & Todos & $\mathbf{F}$ & $\mathbf{M}$ & Todos & $\mathbf{F}$ & $\mathbf{M}$ \\
\hline Todos os tipos de câncer & 45,97 & 90,09 & 109,33 & 46,89 & 91,84 & 117,50 \\
\hline $\begin{array}{l}\text { Lábio, língua, cavidade } \\
\text { oral e orofaringe } \\
\text { (C00-10/C07-08) }\end{array}$ & 0,13 & 0,26 & 6,13 & 3,50 & 0,76 & 7,15 \\
\hline Hipofaringe (C12-13) & 0,65 & 0,00 & 1,33 & 0,65 & 0,76 & 1,32 \\
\hline $\begin{array}{l}\text { Intestino Grosso canal } \\
\text { ânus e ânus (C18-21) }\end{array}$ & 3,13 & 6,14 & 5,07 & 4,40 & 8,88 & 9,00 \\
\hline $\begin{array}{c}\text { Vesícula biliar e vias } \\
\text { biliares extra hepáticas } \\
\text { (C23-24) }\end{array}$ & 1,04 & 2,05 & 1,87 & 0,52 & 2,03 & 1,06 \\
\hline $\begin{array}{l}\text { Cavidade nasal, ouvido } \\
\text { médio e seios da face } \\
\text { (C30-31) }\end{array}$ & 0,13 & 0,00 & 0,27 & 0,13 & 0,25 & 0,26 \\
\hline $\begin{array}{l}\text { Traqueia, brônquios e } \\
\text { pulmões (C33-34) }\end{array}$ & 4,83 & 9,47 & 12,53 & 7,90 & 10,15 & 16,14 \\
\hline $\begin{array}{c}\text { Outros órgãos torácicos } \\
\text { (C37-38) }\end{array}$ & 0,13 & 0,26 & 0,27 & 0,26 & 0,51 & 0,26 \\
\hline $\begin{array}{c}\text { Ossos, articulações e } \\
\text { cartilagens articulares } \\
\text { (C40-41) }\end{array}$ & 0,13 & 0,26 & 0,53 & 0,26 & 0,51 & 1,06 \\
\hline $\begin{array}{c}\text { Nervos periféricos, } \\
\text { sistema nervoso } \\
\text { autônomo e partes moles } \\
\text { (tecidos conjuntivo, } \\
\text { subcutâneo e outros } \\
\text { tecidos moles) }(\mathrm{C} 47+\mathrm{C} 49)\end{array}$ & 0,13 & 0,26 & 1,07 & 0,39 & 0,76 & 0,26 \\
\hline $\begin{array}{c}\text { Rim, Vias urinárias } \\
\text { exceto bexiga (C64-66, } \\
\text { C68) }\end{array}$ & 0,78 & 0,26 & 1,60 & 0,52 & 1,01 & 2,12 \\
\hline $\begin{array}{c}\text { Sistema Nervoso Central } \\
\text { (C70-72) }\end{array}$ & 2,61 & 5,12 & 6,40 & 2,33 & 4,57 & 5,03 \\
\hline Linfoma (C81-85, C96) & 1,96 & 3,07 & 4,00 & 1,55 & 4,31 & 3,18 \\
\hline Leucemia (C91-95) & 2,09 & 2,30 & 4,27 & 1,68 & 3,04 & 3,44 \\
\hline $\begin{array}{l}\text { Corpo uterino e útero, } \\
\text { SOE (C54-55) }\end{array}$ & 0,52 & 1,20 & - & 1,17 & 2,28 & - \\
\hline
\end{tabular}

Legenda: SOE $=$ Sem outras especificações.

Fonte: Dados coletados no Atlas de Mortalidade On-line, organizado pelo Instituto Nacional de Câncer (INCA) (2021). 
Foram analisados também os dados da mortalidade por câncer entre a população de duas cidades do estado do Espírito Santo impactadas pelo desastre da barragem de Fundão.

Em Colatina-ES, a taxa de mortalidade para o período de 2013-2015 foi de 66,30/100.000 habitantes, enquanto no período de 2016-2018 foi de 66,86/100.000 habitantes, representando um aumento de 0,84\%. Considerando apenas a população feminina/100.000 habitantes as taxas foram de 100,50 e 105,14 para os períodos acima, representando um aumento de 4,62\%, enquanto para a população masculina as taxas foram de 134,50 e 135,52 com um crescimento de $0,76 \%$, menor que da população feminina. Os tipos neoplásicos com maior mortalidade foram da traqueia, brônquios e pulmões; intestino grosso e ânus como apresentado na Tabela 6. Vale evidenciar que em Colatina o abastecimento hídrico era exclusivamente retirado do rio Doce (Prefeitura de Colatina, 2016) até 2016, quando foi aberta uma captação auxiliar no rio Santa Maria (Fundação Renova, 2016). 
Tabela 6: Dados de mortalidade por câncer na cidade de Colatina-ES nos períodos de 2013-2015 e 2016-2018 por 100.000 habitantes quanto ao registro considerando a classificação internacional de doença (CID).

\begin{tabular}{|c|c|c|c|c|c|c|}
\hline \multirow{2}{*}{ Colatina } & \multicolumn{3}{|c|}{ 2013-2015/100.00 habitantes } & \multicolumn{3}{|c|}{ 2016-2018/100.000 habitantes } \\
\hline & Todos & $\mathbf{F}$ & $\mathbf{M}$ & Todos & $\mathbf{F}$ & $\mathbf{M}$ \\
\hline Todos os tipos de câncer & 66,30 & 100,50 & 134,50 & 66,86 & 105,14 & 135,52 \\
\hline $\begin{array}{l}\text { Lábio, língua, cavidade } \\
\text { oral e orofaringe } \\
\text { (C00-10/C07-08) }\end{array}$ & 1,37 & 2,70 & 8,35 & 0,82 & 1,61 & 7,71 \\
\hline Hipofaringe (C12-13) & 0,27 & 0,00 & 0,56 & 0,54 & 0,00 & 1,10 \\
\hline $\begin{array}{l}\text { Intestino Grosso canal } \\
\text { ânus e ânus (C18-21) }\end{array}$ & 3,56 & 3,78 & 7,23 & 5,16 & 10,19 & 10,47 \\
\hline $\begin{array}{c}\text { Vesícula biliar e vias } \\
\text { biliares extra hepáticas } \\
\text { (C23-24) }\end{array}$ & 0,27 & 2,16 & 0,56 & 1,36 & 2,68 & 1,65 \\
\hline $\begin{array}{l}\text { Cavidade nasal, ouvido } \\
\text { médio e seios da face } \\
\text { (C30-31) }\end{array}$ & 0,27 & 0,00 & 0,56 & 0,00 & 0,00 & 0,00 \\
\hline $\begin{array}{l}\text { Traqueia, brônquios e } \\
\text { pulmões (C33-34) }\end{array}$ & 5,21 & 10,27 & 15,01 & 3,26 & 6,44 & 14,87 \\
\hline $\begin{array}{l}\text { Outros órgãos torácicos } \\
\text { (C37-38) }\end{array}$ & 0,55 & 1,08 & 1,11 & 0,54 & 0,54 & 1,10 \\
\hline $\begin{array}{c}\text { Ossos, articulações e } \\
\text { cartilagens articulares } \\
\text { (C40-41) }\end{array}$ & 0,82 & 1,08 & 1,67 & 0,54 & 1,07 & 1,10 \\
\hline $\begin{array}{c}\text { Nervos periféricos, } \\
\text { sistema nervoso } \\
\text { autônomo e partes } \\
\text { moles (tecidos } \\
\text { conjuntivo, subcutâneo } \\
\text { e outros tecidos moles) } \\
\text { (C47+C49) }\end{array}$ & 0,27 & 0,54 & 0,56 & 0,27 & 0,54 & 0,00 \\
\hline $\begin{array}{c}\text { Rim, Vias urinárias } \\
\text { exceto bexiga (C64-66, } \\
\text { C68) }\end{array}$ & 0,55 & 2,16 & 1,11 & 0,27 & 0,54 & 2,20 \\
\hline $\begin{array}{l}\text { Sistema Nervoso } \\
\text { Central (C70-72) }\end{array}$ & 2,74 & 5,40 & 5,56 & 1,63 & 4,29 & 3,31 \\
\hline Linfoma (C81-85, C96) & 1,10 & 4,32 & 2,22 & 1,36 & 4,83 & 2,75 \\
\hline Leucemia (C91-95) & 0,82 & 1,62 & 3,33 & 2,72 & 5,36 & 3,86 \\
\hline $\begin{array}{l}\text { Corpo uterino e útero, } \\
\text { SOE (C54-55) }\end{array}$ & 1,64 & 3,24 & - & 1,36 & 2,68 & - \\
\hline
\end{tabular}

Legenda: $\mathrm{SOE}=$ Sem outras especificações.

Fonte: Dados coletados no Atlas de Mortalidade On-line, organizado pelo Instituto Nacional de Câncer (INCA) (2021). 
Um maior aumento na taxa de mortalidade por câncer $(65,70 \%)$ foi observado entre a população da cidade capixaba Linhares nos períodos estudados. Nesta cidade, a taxa de mortalidade/100.000 habitantes para o período de 2013-2015 foi de 37,12, e 61,51 no período de 2016-2018. Considerando apenas a população feminina as taxas foram de 75,10 e 73,38 para os períodos acima, ou seja, apresentando uma queda de 2,29\%, enquanto para a população masculina nos mesmos períodos as taxas foram de 105,37 e 121,57, respectivamente (aumento de 15,37\%). Sendo os tipos neoplásicos mais letais os da traqueia, brônquios e pulmões; intestino grosso e ânus como disposto na Tabela 7. Apesar disso vale lembrar que a cidade de Linhares não coleta água diretamente do rio Doce e sim do rio Pequeno, que é um elo de ligação entre o rio Doce e lagoa Japaranã (Prefeitura de Linhares, 2021; Fundação Renova, 2016). Além disso, desde 2016 devido à turbidez desse corpo d'agua em virtude dos dejetos de mineração 50\% do abastecimento hídrico é retirado de Lagoa Nova (Andrades et al., 2020; Fundação Renova, 2016). 
Tabela 7: Dados de mortalidade por câncer na cidade de Linhares-ES nos períodos de 2013-2015 e 2016-2018 quanto ao registro considerando a classificação internacional de doença (CID).

\begin{tabular}{|c|c|c|c|c|c|c|}
\hline \multirow{2}{*}{ Linhares } & \multicolumn{3}{|c|}{ 2013-2015/100.00 habitantes } & \multicolumn{3}{|c|}{ 2016-2018/100.000 habitantes } \\
\hline & Todos & $\mathbf{F}$ & M & Todos & $\mathbf{F}$ & M \\
\hline Todos os tipos de câncer & 37,12 & 75,10 & 105,37 & 61,51 & 73,38 & 121,57 \\
\hline $\begin{array}{l}\text { Lábio, língua, cavidade } \\
\text { oral e orofaringe } \\
\text { (C00-10/C07-08) }\end{array}$ & 1,87 & 2,10 & 3,69 & 3,26 & 1,65 & 6,44 \\
\hline Hipofaringe (C12-13) & 0,21 & 0,42 & 0,00 & 0,61 & 0,00 & 1,21 \\
\hline $\begin{array}{l}\text { Intestino Grosso canal } \\
\text { ânus e ânus (C18-21) }\end{array}$ & 2,49 & 5,03 & 6,15 & 4,48 & 9,89 & 8,86 \\
\hline $\begin{array}{c}\text { Vesícula biliar e vias } \\
\text { biliares extra hepáticas } \\
(\mathrm{C} 23-24)\end{array}$ & 1,24 & 2,52 & 0,82 & 1,02 & 2,06 & 2,01 \\
\hline $\begin{array}{l}\text { Cavidade nasal, ouvido } \\
\text { médio e seios da face } \\
\text { (C30-31) }\end{array}$ & 0,21 & 0,42 & 0,41 & 0,00 & 0,00 & 0,00 \\
\hline $\begin{array}{l}\text { Traqueia, brônquios e } \\
\text { pulmões (C33-34) }\end{array}$ & 7,47 & 9,23 & 14,76 & 2,24 & 4,53 & 12,88 \\
\hline $\begin{array}{l}\text { Outros órgãos torácicos } \\
\text { (C37-38) }\end{array}$ & 0,21 & 0,00 & 0,41 & 0,00 & 0,00 & 0,00 \\
\hline $\begin{array}{c}\text { Ossos, articulações e } \\
\text { cartilagens articulares } \\
\text { (C40-41) }\end{array}$ & 0,62 & 0,42 & 1,23 & 0,61 & 0,00 & 1,21 \\
\hline $\begin{array}{c}\text { Nervos periféricos, } \\
\text { sistema nervoso } \\
\text { autônomo e partes } \\
\text { moles (tecidos } \\
\text { conjuntivo, subcutâneo } \\
\text { e outros tecidos moles) } \\
\text { (C47+C49) }\end{array}$ & 0,62 & 1,26 & 1,23 & 0,41 & 0,82 & 0,81 \\
\hline $\begin{array}{c}\text { Rim, Vias urinárias } \\
\text { exceto bexiga }(\mathrm{C} 64-66, \\
\text { C68) }\end{array}$ & 0,21 & 1,26 & 0,41 & 1,83 & 0,41 & 3,62 \\
\hline $\begin{array}{l}\text { Sistema Nervoso } \\
\text { Central (C70-72) }\end{array}$ & 1,66 & 3,36 & 5,74 & 2,65 & 3,71 & 5,21 \\
\hline Linfoma (C81-85, C96) & 1,04 & 2,10 & 1,23 & 0,41 & 0,82 & 1,21 \\
\hline Leucemia (C91-95) & 1,24 & 1,26 & 2,46 & 0,81 & 1,65 & 4,03 \\
\hline $\begin{array}{l}\text { Corpo uterino e útero, } \\
\text { SOE (C54-55) }\end{array}$ & 2,49 & 5,03 & - & 1,22 & 2,47 & - \\
\hline
\end{tabular}

Legenda: SOE = Sem outras especificações.

Fonte: Dados coletados no Atlas de Mortalidade On-line, organizado pelo Instituto Nacional de Câncer (INCA) (2021). 


\section{Discussão}

O rompimento da barragem de Fundão representou um dos maiores desastres ambientais da história do Brasil. A liberação dos rejeitos de minério à bacia do rio Doce aumentou consideravelmente a concentração de metais pesados na água, solo e sedimentos, o que pode consequentemente, levar a bioacumulação destes elementos tóxicos, principalmente em organismos aquáticos, que estão diretamente em contato com estes contaminantes (Fernandes et al., 2016).

Os metais pesados são capazes de bioacumular, por meio de absorção, em peixes e outros organismos aquáticos, causando danos a estes organismos, e podendo levar ao processo de biomagnificação, causando riscos à saúde dos consumidores (Neeratanaphan et al., 2020; Godt et al., 2006). Diversos estudos realizados com peixes, demonstraram que metais pesados podem induzir a um processo de estresse oxidativo, ou seja, levaram a um desequilíbrio entre a produção de radicais livre e sua eliminação (Sevcikova et al., 2011; Livingstone, 2006). Portanto, ambientes contaminados por metais pesados podem induzir a uma variedade de efeitos genotóxicos, tais como, quebras de fita simples e dupla, oxidação de bases nucléicas, alterações nos processos de reparo do DNA, entre outros (Monteiro, 2009).

Alguns mecanismos pelos quais metais pesados podem causar genotoxicidade são: i) ferro: geração de espécies reativas de oxigênio (EROs), que podem levar ao estresse oxidativo, processos inflamatórios nas células, ruptura das mitocôndrias, danos ao DNA e apoptose (Batista-Gallep et al., 2018); ii) manganês: incorporação errônea de bases nitrogenadas (Penteado, 2018); iii) cromo: modificação de base nitrogenadas do DNA e quebras de fita; iv) cádmio: indução de estresse oxidativo, substituições e oxidação de bases nitrogenadas, deleções e pontos de mutações ev) chumbo: indução de danos oxidativos, alteração na transcrição gênica, mitogênese, eventos carcinogênicos envolvidos em danos ao DNA, além de alterações genotóxicas indiretas (Neeratanaphan et al., 2020; Arunachalam et al., 2013).

Os estudos abordados nesta revisão (Gomes et al., 2019; Coppo et al., 2018; Quadra et al., 2018; Segura et al., 2016) sugerem o potencial genotóxico das amostras (água, solo e sedimento) analisadas tanto para peixes quanto para células. Possivelmente, as grandes concentrações de metais pesados presentes nos rejeitos de minério liberados após o rompimento da barragem de Fundão são responsáveis pelos estes efeitos tóxicos observados nos animais e plantas analisadas.

Por fim, vale salientar algumas limitações encontradas nos estudos expostos nesta revisão. A principal limitação dos estudos é relacionada com a composição química da região afetada pelos rejeitos de mineração anterior ao derramamento da barragem de Fundão. Isso se deve ao fato de que o rio Doce drena parte do Quadrilátero Ferrífero, área vem sendo explorada pela atividade minerado desde muitos anos, e assim já existe naturalmente uma exposição constante a componentes químicos diversos, incluindo metais pesados (Costa et al., 2003; Xu et al., 2018). Também deve ser considerada a possibilidade de outros contaminantes do rio Doce, tais como descarga de efluentes industriais e de esgoto doméstico sem tratamento (Costa et al., 2003), serem responsáveis pelos efeitos tóxicos observados nos organismos estudados. Ademais, a possibilidade de haver sinergia entre os diferentes metais encontrados em altas concentrações após o acidente com contaminantes diversos deve ser ressaltada, o que aumenta ainda mais os danos tóxicos encontrados, além dos que já foram descritos nesta revisão (Coppo et al., 2018).

Observando-se os dados de mortalidade por câncer é possível perceber que houve um crescimento do número de mortes entre a população das cidades de Governador Valadares, Ipatinga, e Linhares no período de 2015-2018, o que não ocorre na cidade de Mariana e acontece de forma reduzida na cidade de Colatina, 0,87\% de redução. O abastecimento hídrico pode ser um fator correlacionado à incidência de câncer e, consequentemente, à mortalidade, uma vez que águas superficiais que apresentam contaminação com material genotóxico apresentam risco aumentado para o surgimento de câncer (Silva et al., 2013). Corrobora-se a isso as fontes de abastecimento dessas cidades que são, na cidade de Governador Valadares, Ipatinga e Colatina principalmente o rio Doce, um rio contaminado com rejeitos de mineração, e em Mariana, principalmente, do rio Gualaxo e Pancas, respectivamente, que são rios contaminados principalmente com resíduos domésticos (Fernandes et al., 
2016; PERS-ES, 2019). A cidade de Linhares, apesar de não ter seu abastecimento diretamente referente ao rio Doce, é abastecida por um de seus afluentes que foi considerado contaminado devida à turbidez apresentada pela água desse rio (UICN, 2018). Além disso, na região de Linhares residem pescadores tradicionais que dependiam dos recursos do estuário do rio Doce e da costa adjacente, contando principalmente com camarões e peixes (Jankowsky et al., 2020; Andrades et al., 2020). Mesmo com a suspensão da pesca após o desastre, há relatos e indícios de que a captura ilegal de peixes continua, bem como o consumo, ações justificadas pela perda econômica associada ao desastre (Jankowsky et al., 2020). A bioacumulação é reconhecida como uma das principais vias de contaminação entre indivíduos dentro de uma rede trófica. Deste modo, apesar de incipiente é possível crer em uma relação do aumento na taxa de mortalidade por câncer registrados em Linhares com o ambiente contaminado pelos metais presentes na lama de rejeitos que atingiu a região.

Assim como o observado por Silva e colaboradores (2019), os metais encontrados no ambiente contaminado pelos rejeitos de mineração principalmente arsênio, cádmio, chumbo, cromo, mercúrio e níquel, que estão presentes no solo e água da região, estão correlacionados a diversos tipos de câncer, principalmente câncer nas vias aéreas superiores, que foi um tipo tumoral no qual houve grande crescimento. Além disso, este estudo avalia a incidência de câncer especificamente na cidade de Mariana, que apresentam um aumento, apesar desse aumento não ter sido refletido no aumento da mortalidade estudada no presente artigo.

\section{Conclusão}

Os resultados desta revisão sugerem um potencial genotóxico das amostras coletadas na bacia do rio Doce, possivelmente associado à poluição por rejeitos de mineração após o rompimento da barragem de Fundão. As variaçães das taxas de mortalidade observadas nas cidades analisadas parecem estar relacionadas ao estado de contaminação do rio que as abastece, podendo-se sugerir que essa contaminação seja proveniente de rejeitos de mineração no rio Doce. No entanto, são necessários mais estudos para comprovar que as taxas de mortalidade por câncer apresentadas têm correlação direta com o estado de contaminação da água que abastece essas cidades.

Desse modo esse estudo oferece uma visão sobre o efeito a longo prazo da presença de metais pesados no abastecimento de água e como essa situação afeta a população local. Além disso é de extrema importância correlacionar estudos ambientais e sanitários promovendo assim uma discussão mais ampla do impacto dessas características no cotidiano da população.

Por fim, sugere-se a realização de novas pesquisas para corroborar com esta área de estudo, tais como, análises in vitro e in vivo, para verificar o potencial genotóxico e/ou mutagênico destes rejeitos ou de amostras coletadas em locais contaminados por eles. Além de estudos mais profundos, que sejam possíveis avaliar a toxicidade crônica, a fim de que possam analisar se a exposição crônica à água contaminada com os rejeitos da barragem de minério possa contribuir para uma maior incidência e, consequentemente, mortalidade por câncer na população exposta diretamente, auxiliando assim, de forma efetiva com estudos de ecotoxicologia do rio Doce, para estabelecer medidas corretivas e preventivas, no sentido de reduzir os danos à saúde humana e ambiental.

\section{Agradecimentos}

Os autores agradecem à Universidade Federal de São João del-Rei, Campus Centro-Oeste Dona Lindu pelo apoio e suporte. O presente trabalho foi realizado com o apoio da Coordenação de Aperfeiçoamento de Pessoa de Nível Superior Brasil (CAPES) - Código de Financiamento 001, e foi contemplado com a bolsa de iniciação científica PIBIC/CNPq. 


\section{Referências}

ANA - Agência Nacional de Águas. (2016). Encarte Especial sobre a Bacia do Rio Doce - Rompimento da barragem de Mariana. Superintendência de Planejamento dos Recursos Hídricos - SPR. http://arquivos.ana.gov.br/RioDoce/EncarteRioDoce_22_03_2016v2.pdf

Andrades, R., Guabiroba, H. C., Hora, M. S., Martins, R. F., Rodrigues, V. L., Vilar, C. C. \& Joyeux, J. C. (2020). Early evidences of niche shifts in estuarine fishes following one of the world's largest mining dam disasters. Marine pollution bulletin, 154, 111073. 10.1016/j.marpolbul.2020.111073

Arunachalan, K. D., Annamalai, S. K., \& Kuruvaln, J. K. (2013). In-vivo evaluation of hexavalent chromium induced DNA damage by alkaline comet assay and oxidative stress in Catlacatla. American Journal of Environmental Sciences, 9, 470-482. 10.3844/ajessp.2013.470.482

Batista-Gallep, T. B., Pasquoto-Stigliani, T., Guilger, M., Rheder, D. T., Germano-Costa T., Bilesky-José, N., Fraceto, L. F., .... \& Lima, R. (2018). Efeitos de nanopartículas comerciais de óxido de ferro $\left(\mathrm{Fe}_{2} \mathrm{O}_{3}\right)$ : citotoxicidade, genotoxicidade e estresse oxidativo. Química Nova, 41 (9), 974-981. https://doi.org/10.21577/0100-4042.20170271

Braz, S. N., \& Longo, R. M. (2021). Qualidade ambiental das cidades: uso de bioindicadores para avalição da poluição atmosférica. Sustentabilidade, 2, 215198. 10.24220/2675-7885v2e2021a5198

Cruz, F. V. S., Gomes, M. P., Bicalho, E. M., Torre, F. D., \& Garcia, Q. S. (2020). Does Samarco's spilled mud impair the growth of native trees of the Atlantic Rainforest? Ecotoxicology and Environmental Safety, 89(1), 1-12. 10.1016/j.ecoenv.2019.110021

Chakrabarty, S., \& Ghosh, M. (2020). Factors Leading to Disposal of Toxic and Hazardous Sacred Waste and Its Effect on Urban River Contamination: Case of Adi Ganga, Kolkata, India. In: GHOSH, M. Perception, Design and Ecology of the Built Environment A Focus on the Global South. Springer Geography.

Chequer, F. M. D., Angeli, J. P. F., Ferraz, E. R. A., Tsuboy, M. S., Marcarini, J.C., \& Mantovani, M. S. (2009). The azo dyes Disperse Red 1 and Disperse Orange 1 increase the micronuclei frequencies in human lymphocytes and in HepG2 cells. Mutation Research. 676, 83-86. 10.1016/j.mrgentox.2009.04.004

Chequer, F. M. D., Lizier, T. M., De Felício, R., Zanoni, M. V. B., Debonsi, H. M., Lopes, N. P., ... \& Oliveira, D. P. Analyses of the genotoxic and mutagenic potential of the products formed after the biotransformation of the azo dye Disperse Red 1. (2011). Toxicology in Vitro. 25 (8), 2054-2063. 10.1016/j.tiv.2011.05.033

Chou, P., Chen, C., Chen, K., Ko, F., Tsail, T., \& Yeh, Y. (2019). Assessing the endocrine disrupting potentials and genotoxicity in environmental samples from Taiwanese Rivers. Genes and Environment. 41 (24), 1-9. 10.1186/s41021-019-0140-9

CONAMA - Conselho Nacional do Meio Ambiente. RESOLUÇÃO Nº 357. (2005). p 11. http://www2.mma.gov.br/port/conama/legiabre.cfm?codlegi=459

Coppo, G. C., Passos, L.S., Lopes, T. O. M., Pereira, T. M., Merçon, J., Cabral, D. S., \& Chippari-Gomes, A. R. (2018). Genotoxic, biochemical and bioconcentration effects of manganese on Oreochromis niloticus (Cichlidae). Ecotoxicology. 27, 1150-1160. 10.1007/s10646-018-1970-0

Escobar, H. (2015). Mud tsunami wreaks ecological havoc in Brazil. Science. 350 (1), 1138-1139. 10.1126/science.350.6265.1138

Fernandes, G. W., Goulart, F. F., Ranieri, B. D., Coelho, M. S., Dales, K., Boesche, N., \& Soares-Filho, B. (2016). Deep into the mud: ecological and socioeconomic impacts of the dam breach in Mariana. Science, 14(1), 35-45. 10.1016/j.ncon.2016.10.003

Foesch, M. D. S., Francelino, M. R., Rocha, P. A., \& Gomes, A. R. L. (2020). River Water Contamination Resulting from the Mariana Disaster, Brazil. Floresta e Ambiente, 27(4). 10.1590/2179-8087.013218

Fundação Renova. (2016). Colatina e Linhares recebem adutoras alternativas de captação de água. https://www.fundacaorenova.org/noticia/colatina-elinhares-recebem-adutoras-alternativas-de-captacao-de-agua/

Godt, J., Scheigig, F., Grosse-Siestrup, C., Esche, V., Brandenburg, P., Reich, A., \& Groneberg, D. A. (2006). The toxicity of cadmium and resulting hazards for human health. Journal of Occupational Medicine Toxicology. 1(22). 10.1186/1745-6673-1-22

Hatje, V., Pedreira, R. M., De Rezende, C. E., Schettini, C. A. F., De Souza, G. C., Marin, D. C., \& Hackspacher, P. C. (2017). The environmental impacts of one of the largest tailing dam failures world wide. Scientific Reports, 1 (7), 10706. 10.1038/s41598-017-11143-X

IBAMA - Instituto Brasileiro do Meio Ambiente e dos Recursos Naturais Renováveis. (2015). Laudo Tecnico Preliminar: Impactos ambientais decorrentes do desastre envolvendo o rompimento da barragem de Fundão, em Mariana, Minas Gerais, Novembro de $2015 . \quad 38$. http://www.ibama.gov.br/phocadownload/noticias_ambientais/laudo_tecnico_preliminar.pdf.

IGAM - Instituto Mineiro de Gestão das Águas. (2015). Monitoramento da qualidade das águas superficiais do Rio Doce no Estado de Minas Gerais. http://www.igam.mg.gov.br/monitoramento-da-qualidade-das-aguas2.

INCA - Instituto Nacional de Câncer. Atlas de Mortalidade On-line. https://mortalidade.inca.gov.br/MortalidadeWeb/.

Jankowsky, M., De Carvalho, R. M., Gomes, V. A. P., \& De Freitas, R. R. (2020). Peixes e pesca na bacia do rio Doce, uma análise bibliométrica: fish and fisheries on rio doce watershed, a bibliometric analysis. Brazilian Journal of Production Engineering, 14-40. 10.47456/bjpe.v6i8.33769

Gomes L. C., Gomes A. R. C., Miranda T. O., Pereira T. M., Merçon J., Davel V. C, \& Ramos J. P. L. (2019). Genotoxicity effects on Geophagus brasiliensis fish exposed to Doce River water after the environmental disaster in the city of Mariana, MG, Brazil. Brazilian Journal of Biology, 79 (4), 659-664. $10.1590 / 1519-6984.188086$

Livingstone, D. (2003). Oxidative stress in aquatic organism in relation to pollution and agriculture. Revue de Médecine Vetérinarie. 154 (6), 427-430. Disponível em https://www.revmedvet.com/2003/RMV154_427_430.pdf 
Ludke, M., \& André, E. D. A. M. (1986). Métodos de coleta de dados: observação, entrevista e análise documental. Pesquisa em educação: abordagens qualitativas. (p. 25-44). São Paulo: EPU.

Macêdo, A. K. S., Dos Santos, K. P. E., Brighenti, L. S., Windmöller, C. C., Barbosa, F. A., Ribeiro, R. I. M. A., .. \& Thomé R. G. (2020) Histological and molecular changes in gill and liver of fish (AstyanaxlacustrisLütken, 1875) exposed to water from the Doce basin after the rupture of a mining tailings dam in Mariana, MG, Brazil. Science of The Total Environment, 139505. 10.1016/j.scitotenv.2020.139505

Macklin, M. G., Brewer, P. A., Hudson-Edwards, K. A., Bird, G., Coulthard, T. J., Dennis, I. A., \& Turner, J. N. (2006). A geomorphological approach to the management of rivers contaminated by metal mining. Geomorphology, 79 (1), 423-447. 10.1016/j.geomorph.2006.06.024

Medeiros, L. C. C., Delunardo, F. A. C., Simões, L. N., Paulino, M. G., Vargas, T. S., Fernandes, M. N., \& Chippari-Gomes, A. R. (2017). Water-soluble fraction of petroleum induces genotoxicity and morphological effects in fatsnook (Centropomus parallelus). Ecotoxicologyand Environmental Safety. 144 (1), 275-282. 10.1016/j.ecoenv.2017.06.031

Menezes, H. C., \& Faria, A. G. (2003). Utilizando o monitoramento ambiental para o ensino da química. Pedagogia de projetos. Química Nova, 26 (1), $287-$ 290. 10.1590/S0100-40422003000200025

Neeratanaphan, L., Kamollerd, C., Suwnnathada, P., Suwannathada, P., \& Tengjaroenkul, B. (2020). Genotoxicity and Oxidative Stress in Experimental Hybrid Catfish Exposed to Heavy Metals in a Municipal Landfill Reservoir. International Journal of Environmental Research and Public Health. 17(6). 10.3390/ijerph17061980

Monteiro, V. A exposição aguda ao chumbo induz danos no DNA de vários tecidos de peixe Prochilodus lineatus. (2009). (Dissertação de Mestrado em Genética e Biologia Molecular, Universidade Estadual de Londrina). http://www.uel.br/laboratorios/lefa/2009\%20Dissertacao\%20Vanessa.pdf

Oliveira, G. A. R., Ferraz, E. R. A., Chequer, F. M. D., Grando, M. D., Angeli, J. P. F., \& Tsuboy, M. S. (2010). Chlorination treatment of aqueous samples reduces, but does not eliminate, the mutagenic effect of the azo dyes Disperse Red 1, Disperse Red 13 and Disperse Orange 1. Mutation Research, 703 (2), 200-208. 10.1016/j.mrgentox.2010.09.001

Omachi C. Y., Siani S. M., Chagas F. M., Mascagni M. L., Cordeiro, M., Garcia, G., \& Thompson F. L. (2018). Atlantic Forest loss caused by the world's largest tailing dam collapse (Fundao Dam, Mariana, Brazil). Remote Sensing Applications: Society and Environment. 12, 30-34. 10.1016/j.rsase.2018.08.003

Park, S. Y., Lee, S. M., Ye, S. K., Yoon, S. H., Chung, M. H., \& Choi, J. (2006). Benzo a pyrene induced DNA damage and p53 modulation in human hepatoma HepG2 cells for the identification of potential biomarkers for PAH monitoring and risk assessment. Toxicology Letters. 167 (1), 27-33. 10.1016/j.toxlet.2006.08.011

Penteado, F. G. (2018). Avaliação da citotoxicidade e da genotoxicidade de nanopartículas de ferritas de manganês $\left(\mathrm{MnFe}_{2} \mathrm{O}_{4}\right)$ in vitro. (Dissertação de Mestrado em Nanociências e Nanobiotecnologia, $\quad$ Universidade de https://repositorio.unb.br/handle/10482/33013\#: :text=PENTEADO\%2C\%20Felipe\%20Gomes.Avalia\%C3\%A7\%C3\%A3o\%20da\%20citotoxicidade\%20e\% 20da\%20genotoxicidade \%20de\%20nanopart\%C3\%ADculas\%20de,mangan\%C3\%AAs\%20(MnFe2O4)\%20in\%20vitro.\&text=A\%20ferrita\%20de\%20manga n\% $3 \%$ AAs\% $20(\mathrm{MnFe} 2 \mathrm{O} 4, \mathrm{el} \% \mathrm{C} 3 \%$ A 9 tricas\%20 excepcionais\%2C\%20como\%20o\%20superparamagnetismo

PERS-ES - Plano Estadual de Resíduos Sólidos do Espirito Santo. (2019). Diagnóstico sobre a Gestão dos resíduos Sólidos no Espírito Santo. Vitoria - ES. https://seama.es.gov.br/Media/seama/Documentos/Residuos\%20Solidos/11\%20\%20DIAGN\%C3\%93STICO\%20SOBRE\%20A\%20GEST\%C3\%83O\%20DO S\%20RES\%C3\%8DDUOS\%20S\%C3\%93LIDOS\%20NO\%20ESP\%C3\%8DRITO\%20SANTO\%20-\%20VERS\%C3\%83O\%20COMPLETA.pdf

Pohren, R. S., Costa, T. C., \& Vargas, V. M. F. (2013). Investigation of Sensitivity of the Allium cepa Test as an Alert System to Evaluate the Genotoxic Potential of Soil Contaminated by Heavy Metals. Water Air Soil Pollution, 224 (1), 1460-1470. 10.1007/s11270-013-1460-1

Prefeitura de Colatina. (2016) Plano Municipal de Saneamento Básico e Gestão Integrada de Resíduos Sólidos de Colatina. https://lagesa.ufes.br/sites/lagesa.ufes.br/files/field/anexo/Plano\%20Municipal\%20de\%20Saneamento\%20B\%C3\%A1sico\%20de\%20 Colatina.pdf Prefeitura de Linhares. (2021). Hidrografia. https://linhares.es.gov.br/hidrografia/

Quadra, G. R., Roland, F., Barros, N., Malm, O., Lino, A. S., \& Azevedo, G. M. (2019). Far-reaching cytogenotoxic effects of mine waste from the Fundao dam disaster in Brazil. Chemosphere. 215, 753-757. 10.1016/j.chemosphere.2018.10.104

Rother, E. T. (2007). Revisão sistemática X revisão narrativa. Acta Paulista de. Enfermagem, 20(2):v-vi. https://www.scielo.br/j/ape/a/z7zZ4Z4GwYV6FR7S9FHTByr/?lang=en\&format=pdf

SEDRU - Secretaria de Estado de Desenvolvimento Regional, Política Urbana e Gestão Metropolitana. (2016). Avaliação dos efeitos e desdobramentos do rompimento da Barragem de Fundão em Mariana-MG. 1, 284. http://www.agenciaminas.mg.gov.br/ckeditor_assets/attachments/770/relatorio_final_ft_ 03_02_2016_15h5min.pdf

Segura, F. R., Nunes, E. A., Paniz, F. P., Paulelli, A. C. C., Rodrigues, G. B., Braga, G. U. L., \& Batista, B. L. (2016). Potential risks of the residue from Samarco's mine dam burst (Bento Rodrigues, Brazil). Environmental Pollution. 218, (1), 813-825. 10.1016/j.envpol.2016.08.005

Sevcikova, M., Modra, H., Slaninova, A., \& Svobodova, Z. (2011). Metals as a cause of oxidative stress in fish: A review. Veterinární Medicína. 56, 537-546. 10.17221/4272-VETMED

Silva, G. H. da, Messias, T. G., Leme, D. M., \& Monteiro, R. T. R. (2013). Mutagenicidade e genotoxicidade em águas superficiais e subterrâneas antes e após o tratamento de água. Holos Enviroment. 13 (1), 64-73.

Silva, G. R. R., Rudy, J. T., Matos, K. F. R., Silva, E. L., \& Gurgel, H. (2019). Análise dos possíveis efeitos na incidência de neoplasias referentes a intoxicação por metais pesados após o desastre ambiental da Samarco em Mariana MG. In Simpósio Nacional de Geografia da Saúde, 9, (p. 1-10). Blumenau, Santa Catarina.

Souza, C. L. R., Costa, V. B., Pereira, S. F. P., Silva, D. C. M., \& Sarpedonti, V. (2016) Impactos da vida urbana na qualidade da água e nas comunidades de larvas de peixes em dois riachos da Amazônia brasileira. Revista Ambiente e Água. 11, (1), 13-23. 10.4136/ambi-agua.1763 
Research, Society and Development, v. 10, n. 7, e17010716374, 2021

(CC BY 4.0) | ISSN 2525-3409 | DOI: http://dx.doi.org/10.33448/rsd-v10i7.16374

Tice, R. R., Agurell, E., Anderson, D., Burlinson, B., Hartmann, A., Kobayashi, H., \& Sasaki, Y.F. (2000). Single cell gel/comet assay: Guidelines for in vitro and in vivo genetic toxicology testing. Environmental and Molecular Mutagenesis, 35 (1), 206-221. 10.1002/(sici)1098-2280(2000)35:3<206::aidem8>3.0.co;2-j

UICN-União Internacional para Conservação da Natureza. (2018). Riscos da supressão de fluxos naturais em um sistema fonte-mar - O caso da Lagoa Juparanã, Espirito Santo, Brasil. Painel do Rio Doce - Questões em Foco n ${ }^{\circ} 3$. https://www.iucn.org/sites/dev/files/rio-doce-panel-issue-paper-3-pt_0.pdf

Vendemiatti, J. A. S., Camparotto, N. G., Vidal, C., Cristale, J., Agapito, E. V. M., Oliveira, A. C., \& Prediger, P. (2021). New benzotriazoles generated during textile dyeing process: Synthesis, hazard, water occurrence and aquatic risk assessment. Journal of Hazardous Materials, $403,123732$. 10.1016/j.jhazmat.2020.123732

Weber, A. A., Sales, C. F., Faria, F. S., Melo, R. M. C., Bazzoli, N., \& Rizzo, E. (2020). Effects of metal contamination on liver in two fish species from a highly impacted neotropical river: A case study of the Fundão dam, Brazil. Ecotoxicology and Environmental Safety, 190. 10.1016/j.ecoenv.2020.110165

Xu, F., Hu, B., Li, J., Cui, R., Liu, Z., Jiang, Z., \& Yin, X. (2018). Reassessment of heavy metal pollution in river in sediments of Hainan Island, China: sources and risks. Environmental Science and Pollution Research, 25 (2), 1766-1772. 10.1007/s11356-017-0562-5 